Article

\title{
Exploring Embodied Place Attachment Through Co-Creative Art Trajectories: The Case of Mount Murals
}

\author{
Ruth Segers ${ }^{1, *}$, Karin Hannes ${ }^{2}$, Ann Heylighen ${ }^{1}$ and Pieter Van den Broeck ${ }^{1}$ \\ ${ }^{1}$ Department of Architecture, KU Leuven, Belgium; E-Mails: ruth.segers@kuleuven.be (R.S.), \\ ann.heylighen@kuleuven.be (A.H.), pieter.vandenbroeck@kuleuven.be (P.V.D.B.) \\ ${ }^{2}$ Faculty of Social Sciences, KU Leuven, Belgium; E-Mail: karin.hannes@kuleuven.be \\ * Corresponding author
}

Submitted: 25 April 2021 | Accepted: 17 August 2021 | Published: 30 November 2021

\begin{abstract}
The built and living environment in the Flemish region in Belgium is evolving noticeably. It is densifying at an ever-faster pace and, along the way, becoming increasingly unfamiliar to its inhabitants. Many people face profound difficulties in autonomously and positively dealing with such drastic changes, causing their feeling of home to waver. Triggered by these challenges and supported by the local authority of a Flemish town, the experimental and co-creative art project Mount Murals set out to stimulate new embodied interactions between and among local residents of various ages and backgrounds and with their built environment. These include remembering place-related sentiments, being aware of body language that plays between participants while co-creating and sensing an invigorating stimulus when seeing results. Awakening intrinsic appreciation in people for their own environment and associated social relationships stimulates an inclusive dealing with estranged relationships in space. Referring to the relational neuroscience principles attachment, co-creating and co-regulating as a modus of relational resonating, we explore how and under which conditions Mount Murals' co-creative art trajectory supports an evolving embodied place attachment, an essential element of the sense of belonging, in participants. By embedding assets inherent to art creation in action research and starting with meaningful everyday objects, Mount Murals carries forward an art expression that considers the co-creation process and its co-creative products as equally important.
\end{abstract}

\section{Keywords}

co-creative art; co-regulating; embodied place attachment; relational resonating; sense of belonging

\section{Issue}

This article is part of the issue "Art and Design for Social Inclusion in the Public Sphere" edited by Karin Hannes (KU Leuven, Belgium).

(C) 2021 by the authors; licensee Cogitatio (Lisbon, Portugal). This article is licensed under a Creative Commons Attribution 4.0 International License (CC BY).

\section{Introduction}

Over the last 25 years, Flanders (Belgium) faced not only the consequences of rapidly growing globalisation, digitalisation and super diversity, but also a steep rise in the densification of its built and living environment and failed attempts to slow down soil sealing (the "concrete stop"). The ever-faster pace of change has triggered, among others, debates on identity loss, exclusion of large population groups, and difficulties of social integration. Consequently, many people struggle with alienation, wavering feelings of home and social connection, feelings of losing their identity, and difficulties in expressing their sense of belonging to the territory. In short, the living environment becomes increasingly unfamiliar to those living (in) it. Several authors relate challenged feelings of belonging partially to problems of depression, and mental health in general (Hunter et al., 2017; McLaren \& Challis, 2009). Research by Hunter et al. (2017) shows that greater feelings of belonging are associated with less frequent symptoms of depression, and this both in racially mixed and racially non-mixed 
neighbourhoods. Also, Fitzgerald (2018) interlinks place, change, status, and the rise of radical politics throughout Europe. Similarly, losing sense of belonging might help explain the success of populist, nationalist, and separatist political parties in Flanders.

Triggered by these challenges, aiming to restore feelings of attachment to place and to stimulate the inclusion of parts of the population, the municipality of Heist-opden-Berg and the first author of this article joined forces to implement a co-creative art trajectory, Colour and Shape Heist-Goor, including several artistic workshops in "church village" Heist-Goor. The one-year trajectory led to the collective implementation of a work of art in a characteristic public space of this church village which counts 1500 post boxes. Heist-op-den-Berg had seen a growing tension between the core municipality and its sub-municipalities, originating, among others, in the 1976 merger that reduced the number of Flemish municipalities from 2359 to 308 today. Over time the accompanied rationalisation and centralisation of public services has led former autonomous municipalities and church villages like Heist-Goor (that never was an independent municipality; see Figure 1), to become so called "sleeping villages," where people hardly connect

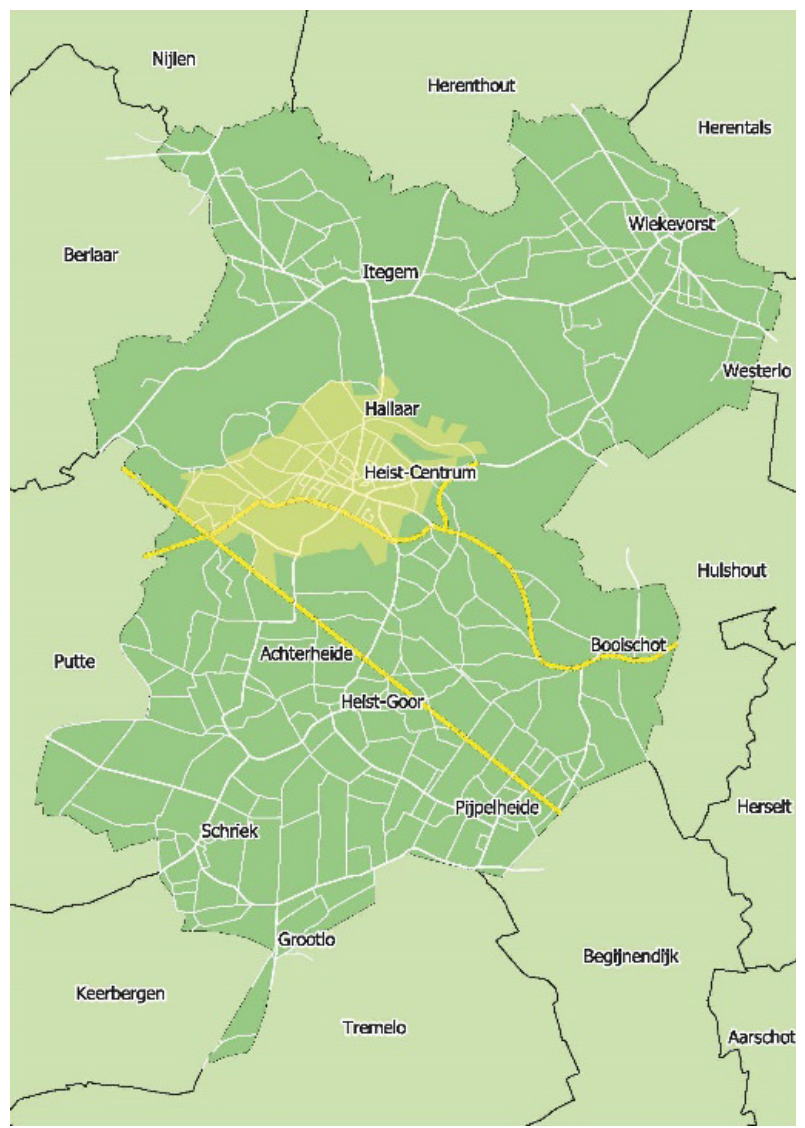

Figure 1. Merger municipality Heist-op-den-Berg (dark green) with its core municipality Heist-Centrum (yellow) and sub-municipalities and church villages, including Heist-Goor. Image developed by the Municipality of Heist-op-den-Berg. with public place. This trend is reflected in the decline of the local economy, an ageing population, a withdrawal of public services like public transport, public library and art school facilities, and a drastic reduction of locally organised activities. These functionalities also refer to particular places or buildings. Because inhabitants of sub-municipalities, church villages, and hamlets are gradually excluded from nearby functionalities and what is on offer for them, a tension exists between them and inhabitants of the core municipality (in this case Heist-op-den-Berg; see Figure 1).

Finding one's place in this world is a crucial aspiration, regardless of background, age, gender or other characteristics. For most people it somehow is an intriguing life time "occupation." The word "place" itself carries both a spatial and a political meaning (Hayden, 1995, p. 15): It carries the resonance of a location or the homestead, but also refers to a position in social hierarchy or one's life purpose; hence the proverbs "knowing one's place" or "feeling out of place." In this article we argue that "place," as a location, literally "holds" the intricate relationship between the social and the world including the material and biological we live in. Furthermore, there is a direct relationship between a particular place and people's universal need to connect with each other (Baumeister \& Leary, 1995). The question then is: How can we understand this relationship and, more importantly, how can we animate or revitalise it?

To address this question, we approach Mount Murals' co-creative art trajectory Colour and Shape Heist-Goor. Mount Murals is a project that generates and implements embodied art trajectories. It is initiated by the first author of this article, a researcher, painter and emotionally attached inhabitant of Heist-op-den-Berg. In this project, she was guided by the other authors and worked together with professional (research) artists to explore to what extent, how, and under which conditions this collective art expression supports an evolving embodied place attachment among participants. After the introduction, Section 2 of this article mobilises a relational socio-spatial theory to unpack sense of belonging as an embodied process of (place) attachment. It then links this theory with the revitalising characteristics of three relational resonating principles: attachment, co-creating, and co-regulating. These principles, among others, have been investigated in art therapy research to revitalise interpersonal attachment and resilience (Hass-Cohen \& Clyde Findlay, 2015).

The first author acknowledged the relational resonance principles at work in the actions that are embedded in the Idiosyncratic Machine (IM) workshop, designed by artistic researcher Kristof Van Gestel (KASK \& Conservatorium, School of Arts HOGENT, and HOWEST), and connected them with place in the pilot art trajectory Colour and Shape Heist-Goor. Section 3 describes this trajectory and specifies how it applies action research to evaluate those actions that revitalise inhabitants' feelings of home and inclusion. The action 
research methodology is further enriched with a phenomenological approach of the first person which elaborates on two assets of art creation.

Section 4 examines the findings of inhabitants' evolving place attachment. Participants' feelings regarding initial place attachment have been documented through object elicitation and written down on cards by them. Photographs of actual actions that refer to relational resonating have been taken and related feelings have been documented through (recorded) semi-open interviews, participative observation of oral explications during the first workshop series, and written explication in emails and comments in social media after the workshops. The feelings have been orally discussed again, during the final workshop and the inauguration of the work of art in public place, seven to nine months after the first workshops.

The conclusion (Section 5) highlights the elements that relate to an evolved feeling of place attachment in participants of the Colour and Shape Heist-Goor trajectory, especially to actions and experiences of participants in the three IM workshops.

\section{Linking the Embodied Processes of Place Attachment and Emotional Attachment}

Research on attachment to place has been quite multivocal, with ubiquitous notions and manifold interpretations, often holding non-corresponding definitions. Further research would benefit from more attention to notions like sense of community, community attachment, inclusive space, place dependence, including the notions of place identity, place attachment, sense of belonging, and sense of place, which are considered in this section. In general, two elements come to the fore in definitions of attachment to place: (a) a person's experience of being included, valued, needed, accepted as a human being, and (b) a person's perception that their characteristics resonate with the environment. Hagerty et al. (1992, p. 173) combine these elements in their definition of sense of belonging, "the experience of personal involvement in a system or environment so that persons feel themselves to be an integral part of that system or environment." Seen as such, sense of belonging links two distinctive concepts: place identity and place attachment. Place identity is the process by which, through interaction with places, people describe themselves in terms of belonging to a specific place, which then becomes a component of their personal identity (Proshansky et al., 1983; Stedman, 2002). Although this definition assigns significance to a place for developing the self and personal identity, it does limit the concept's scope to those dimensions of the self that develop in relation to a place's physical and material aspects. The second concept, place attachment, refers to an affective and secure link with a place. The place can be any place, regardless of size or physical character, which becomes a centre of meaning. The main characteristic of place attachment would be the tendency of the individual to maintain closeness to the "object" (Hidalgo \& Hernandez, 2002). This approximation misses the elements of process and identity.

Sense of belonging strongly resonates with having a sense of place. Harrison and Dourish (1996) define sense of place as a common sense of appropriate behaviour in a context where action can be taken and interpreted. According to them the knowledge to act properly in a place is acquired through active and committed participation in that place. Hence, geographer and place research pioneer Tuan $(1975$, p. 164) writes: "It takes time to know a place, the passage of time itself does not guarantee a sense of place. If experience takes time, the passage of time itself does not ensure experience." It is through experiencing that "spaces" can become meaningful "places." Sense of place is what makes a space specific. The specificity relates not only to the environment's physical characteristics, but also to affections, meanings (counting memories and associations) and the activities offered by the place, including social interactions associated with it (Zeisel, 2006). Members of any other culture, such as newcomers to a neighbourhood, learn through socialisation the local culture and the role they can play in it. Learning takes time and commitment. Therefore, establishing a relationship with a place can be considered as a lifelong and changing process.

However, in general, and for what matters in our study, we see a clear difference between the human evaluation "I feel at home, in this place" and "I live in this place." Both evaluations can but do not necessarily coincide. It is not because person $A$ is attached to a particular place that it is a part of their actual life or place identity. They could have a feeling to belong to a place, but not the ability or wish to live there (Hidalgo \& Hernandez, 2002). Vice versa person B can live in a particular place without ever developing a feeling of being at home. Hence place attachment and place identity must be evaluated differently. Moreover, place attachment can become de-duplicated (Segers, 2018). In the context of migration, and after a period of time, some people find themselves in a situation where they feel at home in more than one place but are not fully at home in either of the concerned places. In this context we can speak of a relative feeling of being excluded. Very often this exclusion refers to places one is attached to, the place one is located in, and the other place(s). Place identity refers to one particular place in a specific time period. Both evaluations, place attachment and place identity, can change over time, the former through a personal and processual transformation in one place, in the latter change coincides with relocation or refurbishment.

Place attachment is believed to be given rise to by numerous variables, including mobility, length of residence, repeated contact or experience, shared meaning and "feeling included" (Hay, 1998). Tuan (1975) underlined the importance of the passive character of experiencing the environment. Very often experience is 
something invisible, hidden from the public eye and even from the experiencer themselves. It is not uncommon that small pleasures or irritations of day-to-day living are felt very deeply, but difficult to articulate, or fail to be acknowledged. "Think about the barely registered but omnipresent ambience of sound and smell, the feel of air, soft soil, and hard ground, the happy accidents and occasional blows of fate" (Tuan, 1975, p. 161).

According to recent developments in neuroscience, for which May-Britt Moser, Edvard I Moser, and John O'Keefe received the 2014 Nobel Prize in physiology or medicine, place and grid cells in our brain record our experiences of places as memories. The memories stored in those cells constantly inform our experiences of those places (Moser et al., 2015). This inner positioning system, which enables us to navigate, is fundamental to our existence. It gives us a sense of place, a perception of position in the environment. During navigation, it is interlinked with a sense of distance, based on motion and knowledge of previous positions. Based on those findings, Relph (2015) claims that without a sense of place, however acquired and stored in memory, there can be no sense of belonging. So contrary to popular belief, the proverb "home is where the heart is" must be understood as an embodied connection with a particular place, not a "merely" sentimental or socially induced one. What is more, it is the effective embedding of the experience of place in the body, over a period of time, that leads to attachment. As such we follow Twigger-Ross and Uzzel's (1996) idea that all aspects of identity have, to some extent, place-related implications, rather than a separate part of identity being concerned with place (Stedman, 2002). We similarly adhere to Marsh et al.'s (2009) suggestion to:

Move closer to a more radical, yet holistic understanding of the body's participation in the creating of meaning, where [physical] environments provide an additional embedded context for meaningfulness. Where it is worth while to develop more of an interest in studying 'doing' and thus stripping away the notion that it is merely the cognitive system that imposes meaning and value on things in this world. (Marsh et al.'s, 2009, p. 1221, emphasis added by the author)

Consequently, we endorse the claim that the built environment is not "merely an arena in which social life unfolds, but rather a medium through which social relations are produced and reproduced" (Gregory \& Urry, 1985, p. 3). Moreover, it is capable of "signifying a difference between those that belong-literally and figuratively-and those that not-belong" (Pérez Liebergesell et al., 2021, p. 4). Accordingly, we argue that the built environment is a perfect starting ground and "ally" for promoting (place) identity and place attachment and thus a sense of belonging.

For this purpose, we use insights from relational neuroscience, which have been applied in art therapy to promote interpersonal attachment (Hass-Cohen \& Clyde Findlay, 2015). Psychologists Hass-Cohen and Findlay (2015) highlight the activation and processing of relational schemas and other memories in our brain in the context of healthy (interpersonal) attachment and resilience. In very creative and practical ways, they show how performing certain actions when making artwork influences our brain's learning process. Because our brain tends to be rather plastic and adaptable, both negative and positive experiences can change its functioning and structure (Badenoch, 2008).

Our study revolves around the notion of attachment and therefore highlights relational resonating, one of six CREATE principles from Hass-Cohen and Findlay's (2015) art therapy relational neuroscience (ATR-N) approach. The remaining principles are creative embodiment, expressive communicating, adaptive responding, transformational integrating and empathising, and compassion. All six principles come with guidelines that have been developed to support the bonding processes between, e.g., parents and children. In this article we zoom in on relational resonating, an overarching notion that refers to the special relationship we enter whenever we interact with another being. It occurs when you feel smoothly but stably attuned to yourself and to another person. This particular relationship can enhance positive experiences and help to let go of negative ones. The attunement can be animated through, e.g., co-creation, co-consciousness, co-regulation. Sharing with others, being heard and feeling that your own experience is felt empathically by another person reinforces emotional regulation. That is, these experiences have the inherent ability to fine-tune our emotions, update our autobiographical memory, and contribute to acquiring attachment.

Central to the creative principle of relational resonating is the notion of emotional attachment. Emotional attachment styles depend on experience and thus can change during a person's life (Siegel, 2012). A person's attachment style and history influences their ability to access and share autobiographical memories. Those with a secure relational history may use positive past memories for comfort, while those with less secure models or chronic trauma histories may have more difficulty recalling cohesive past stories (Hass-Cohen \& Findlay, 2015).

Two ATR-N skills linked to attachment are co-creating and co-regulating. Co-creating, both side by side and together, and responding to responses within and outside creative workshop settings, allows for the attachment relationship to develop. The attunement through co-creation provides the opportunity to experience and develop emotional attachment. Co-regulating refers to our ability to calm our self. This is basically an interpersonal, non-verbal, right-brain to right-brain communication, and lies at the heart of relational resonance. The ability to self-regulate and self-soothe is central to successful interpersonal interaction. Without co-regulatory experiences, cognitive and emotional 
brain capacities can diminish. This is because a tuned attachment relationship removes some of the burden that independent emotional and behavioural control places on the prefrontal cortex function (Hughes et al., 2012). Co-regulation involves a dynamic, mutual and iterative process that supports systematic recovery and personal development and change (Tronick \& Beeghly, 2011). Well-understood body communication calms those involved in communicating. An example from classical experimental psychology is that rocking together in rocking chairs, unintentionally attuned to each other's rhythm, can be hugely reassuring (Richardson et al., 2007). Our study explores the "interpersonal" character of place attachment. The "other" is an element of the environment, be it a pen, a cat, a street crossing or nature, it is about interacting with the "outside world," and the embedding of this "interpersonal" attachment in the wider setting of place.

\section{Mount Murals' Phenomenological Artistic Action Research Trajectory}

\subsection{The Colour and Shape Heist-Goor Art Trajectory}

The first author organised over a one-year period an iterative process of three artistic workshop series at various well-known locations in the village: the dining space of the local bakery, the rehearsing space of the local brass band, the refectory of the local primary school and the actual location of the physical art work intervention, in front of the village church. In each series one particular workshop was organised at least twice and was guided by a professional artist, who uses their own methods to create art together.

In the first two workshop series, the first author collaborated with artistic researcher Kristof Van Gestel and public silk screen printing workshop Gezeever. Kristof's work of art Idiosyncratic Machine was organised three times in the first workshop series. The first author enriched the IM workshop process with emotional links to local (persons') places as embedded in the objects that started off the creative process. All IM workshop participants were invited to bring along an object that symbolises their connection with the place and "holds" a memory of a local person, event or place. Thirty-seven individuals brought along an object and were asked to write on a card the attached memory and corresponding emotion. Figure 2 shows a compilation of the objects with related memories reflecting place attachment. Participants were then invited to outline their objects on paper (see graphic behind the text in Figure 2 ). The in-between spaces were then filled with shading in colours; new shapes were outlined on chalk paper and cut out; cut outs were transferred to coloured paper and cut out again (see Figure 3 ). In this way the data collecting technique of object elicitation, which facilitates discussing sensitive issues like personal feelings, was interwoven with the art trajectory.

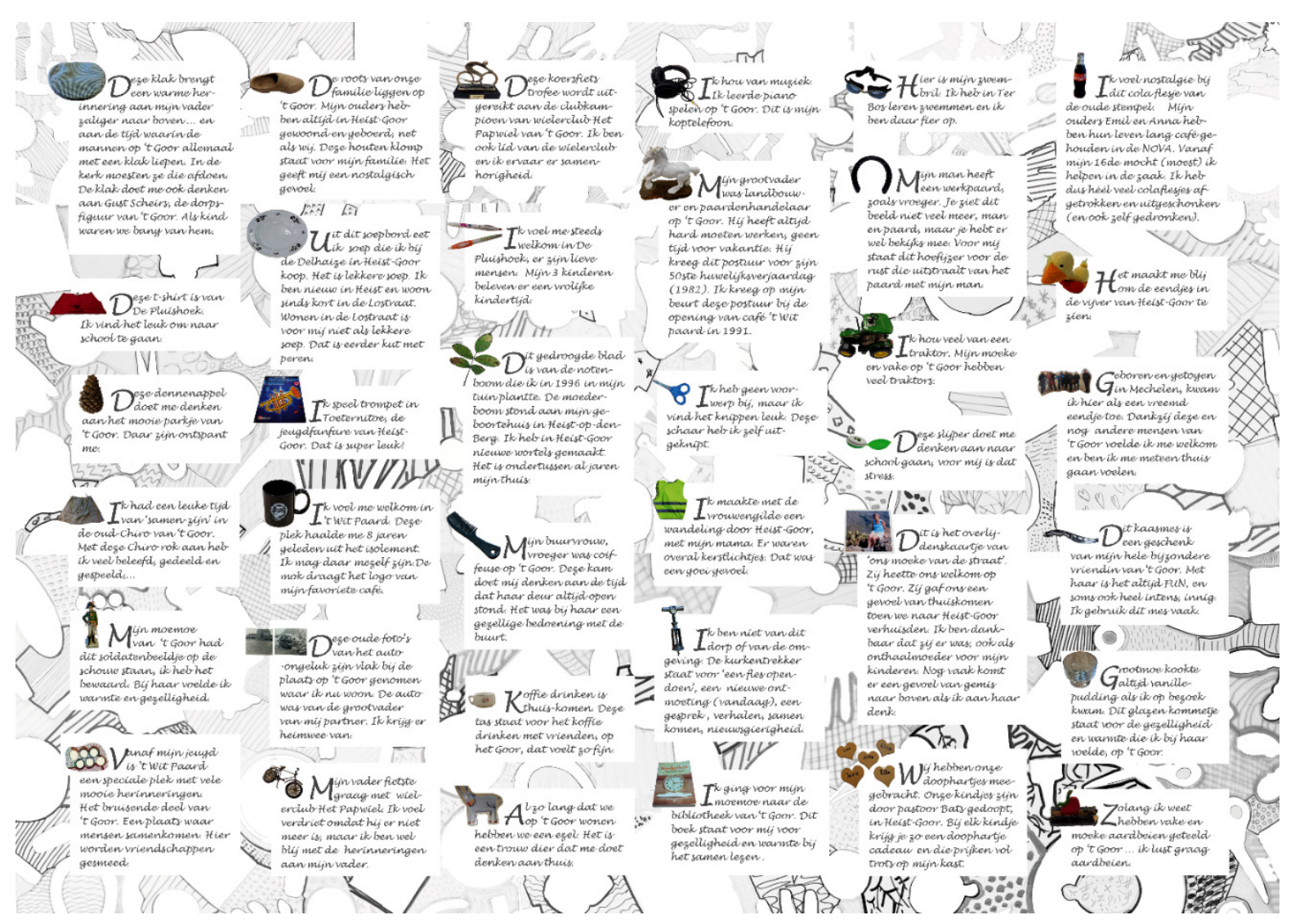

Figure 2. A compilation of object-related memories, showing participants' attachment to Heist-Goor. Source: Ruth Segers. 

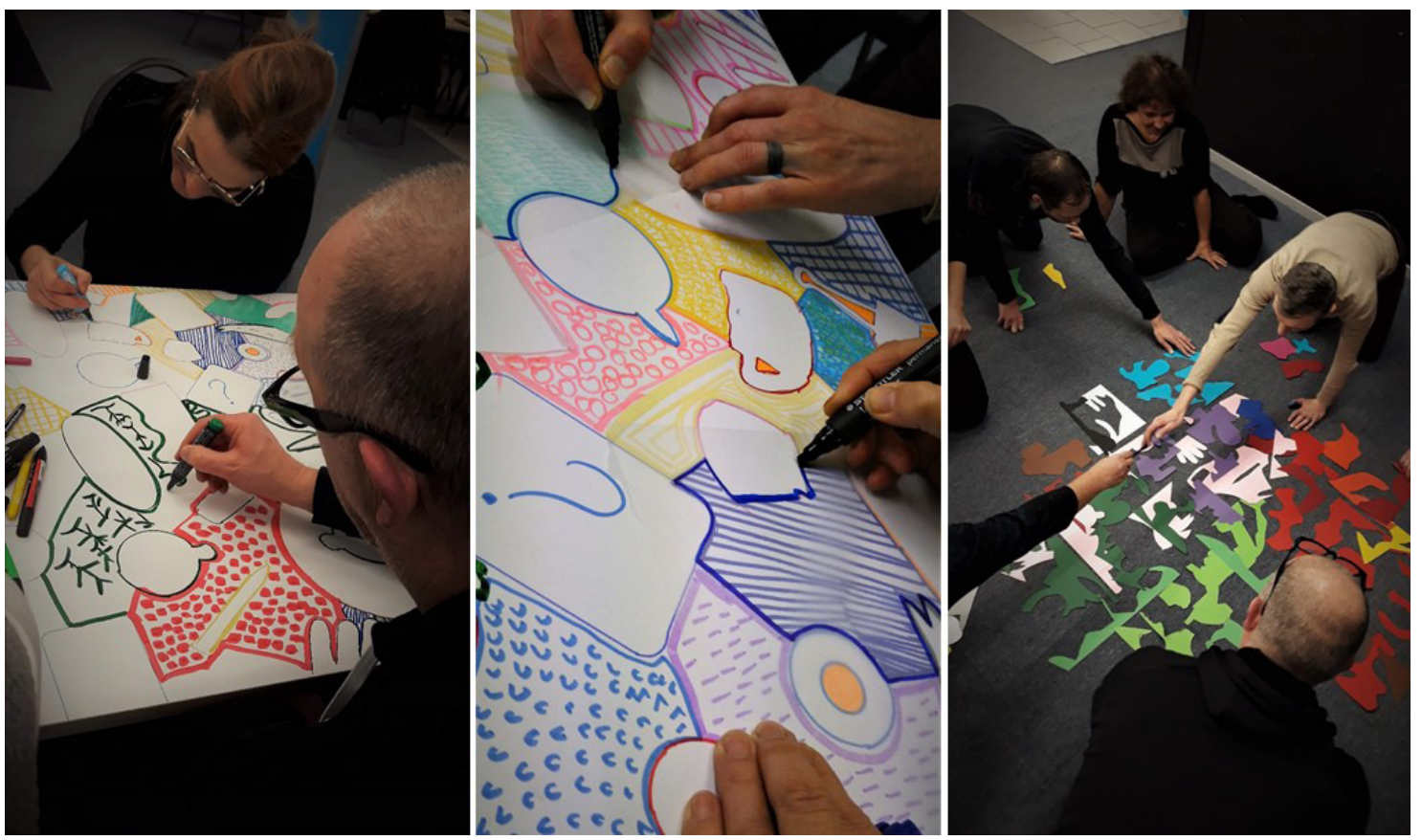

Figure 3. The IM workshop reworks objects into a "landscape of shapes." Source: Frédérique Rennuit.

While the workshops were open to everybody with a certain affinity with the church village, inclusivity in this trajectory relates predominantly to age, social background and gender characteristics. Also, one needed to be able to manipulate a felt pen and scissors. For these reasons the embodied experiences in the workshops (see Section 4) make taking part especially stimulating for deepening intergenerational and crossbackground interaction and bonding. Bossuyt (2019, p. 200) describes IM as an art event in which participation is just as important as the result and in fact essential to it. He sees it as "a drawing and cutting machine that generates shapes in accordance with a series of instructions laid down by the artist." Van Cauteren (2019, p. 36) names it "a matrix, at the core of its operation lies experiencing and process. The art work becomes secondary, encounter and connection the core."

In the last workshop series, participants implemented a tailor-made design of IM shapes for three locations in between primary school and church: two walls of the electricity supply house in the school's front yard, the side façade of the café next to the school, and the space along the pedestrian crossing between school and church (see Figures 4 and 5). Each workshop provided a joint result, whereby each participant recognised their own contribution.

In total, 27 boys and girls and 43 men and women, from age five to 81 , have participated in one or more workshops of the Colour and Shape Heist-Goor art trajectory. The church village is not very diverse in the sense of ethnicities involved, however in the participants we see very diverse ages and socio-economic backgrounds, including farmers, employees, university students, pensioners (of which several teachers), a café owner, house- wives, schoolchildren; among those, three artists and two pensioned art teachers were involved. The other participants had no experience with art making. However, all of them had an affinity with the church village. Their affinity was inquired in the enrolment form through statements like "I was born in the village," "I work for or in the village," "I live in the village," "My child goes to school in the village," etc. The answers revealed that people living in the village, but not born there, consider themselves as co-belonging to the village where they were born, whether they had been living in Heist-Goor for 20 or 50 years. Similarly, people who had left the village 50 years ago, but were born there, still consider themselves as a member of the community.

In general, the full art trajectory brought discussion, ownership and liveliness to the place in between the local church and primary school. As one local, who did not participate, commented on Facebook: "Thank you, dear lady, for beautifying our village" (Segers, 2020). A local's Facebook post about the painting along the pedestrian crossing, received 84 reactions discussing benefits of and objections to this particular implementation (Heist-op-den-Berg vroeger en nu, 2020). Moreover, the project brought people together who would never have met each other: A young mother who was looking for help in educating her new puppy dog met a pensioned widower who loved to share his talents as a dog trainer. The project also brought redirection in people's lives: A 20-year-old carpenter, after participating in the silk screen printing workshop, quit his job as a roofer, bought a silk screen printing frame and started the new academic year doing graphic design. Also, all passersby and members of this local community encounter the result of the art work in public space on a regular basis. 

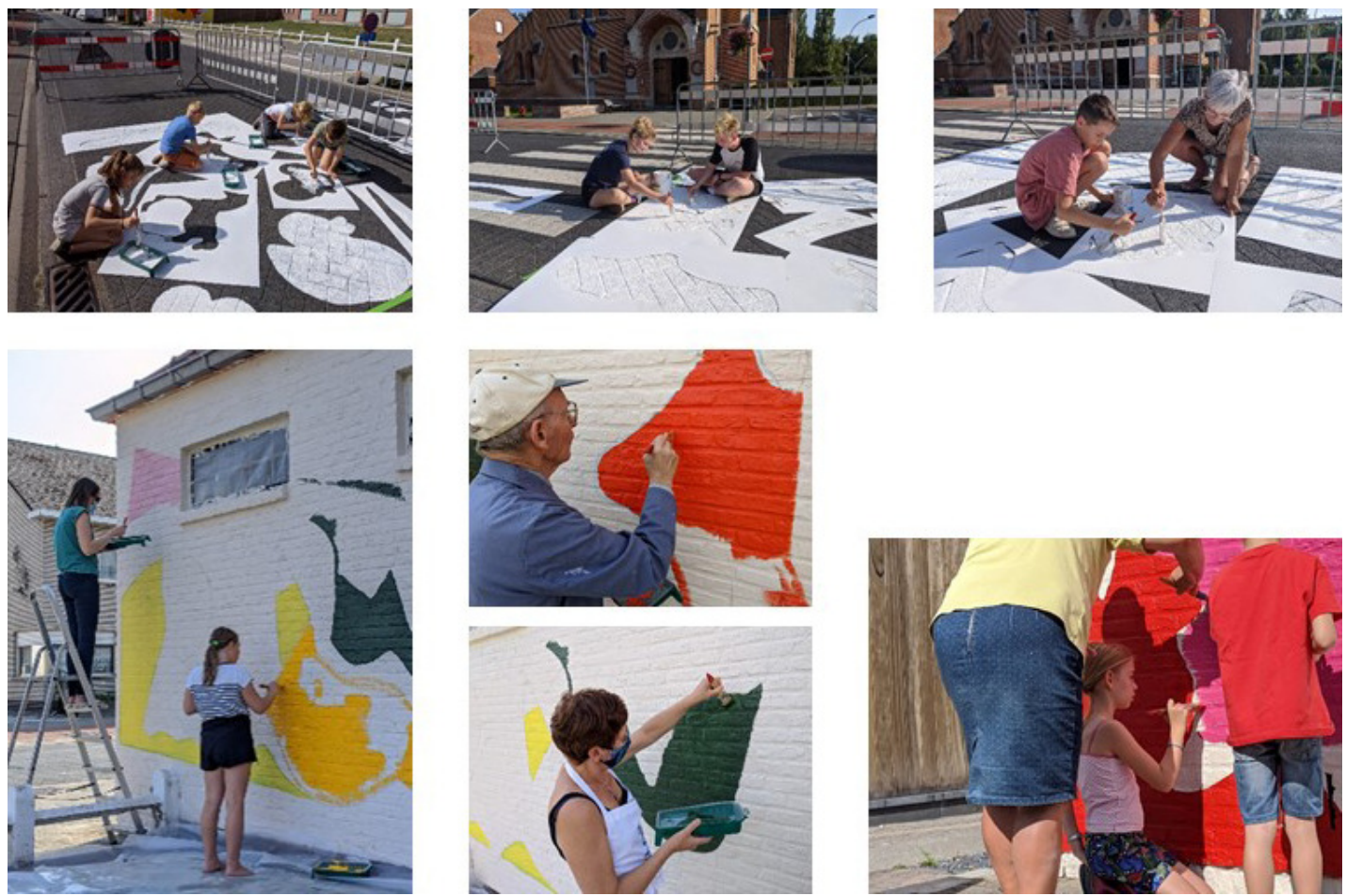

Figure 4. Implementation and results of the Colour and Shape Heist-Goor artistic trajectory in a characteristic public space of Heist-Goor. Source: Ruth Segers.

\subsection{Phenomenological Artistic Action Research}

The Colour and Shape Heist-Goor trajectory ran in crosspollination with the province-of-Antwerp-led participation project Resilient Villages Heist-Goor, implemented by the municipality of Heist-op-den-Berg. The first author attended to this participation project, which guided her in the choice of the location of the artefact for pub- lic space: The environment of the primary school and the church is a place with a distinct character that needed some upgrading. In meeting this place-based need, the trajectory met the first out of four characteristics of action research (Bradbury Huang, 2010). A second characteristic is met in promoting co-production that was developed on the basis of an iterative process and adopted in all involved steps. The trajectory takes
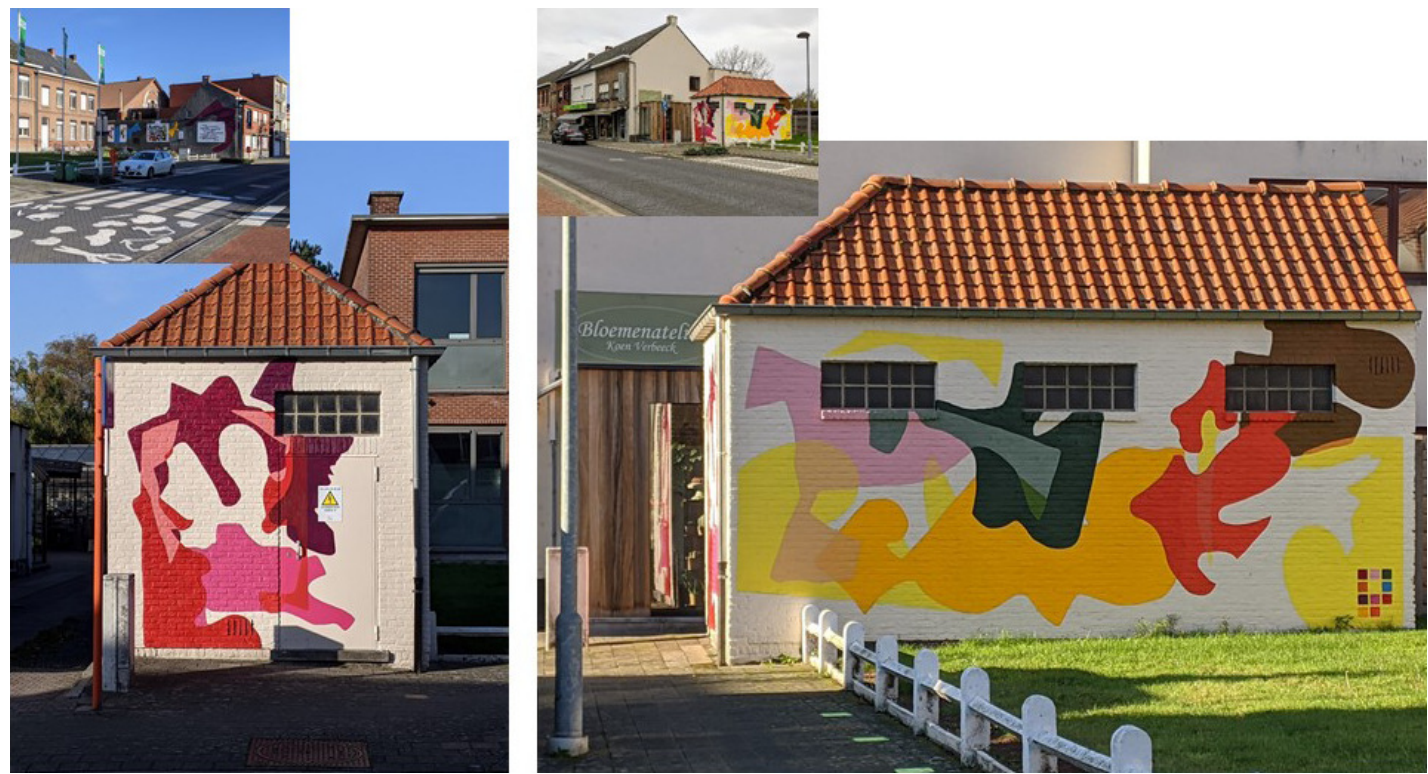

Figure 5. The electricity supply house is the accomplishment of 35 participants working together. Each shape is cut by someone, each colour is printed by someone else, and the actual painting on the wall is done by 12 other participants. Source: Ruth Segers. 
into account context and content by giving every participant an equal partnership in producing outcomes as well as in research. Action research seeks inclusive collaboration, which can be defined as an exchange where all participants benefit from the encounter (Sennet, 2012). The trajectory met a third characteristic by inviting participants to talk about their emotions in relation to the actions and ambiance in the first workshop and about the progressing emotions they witnessed with regard to objects and shapes created in the project workshops (see Section 4). In doing so, the project included reflexivity. Those involved were asked to adopt and make explicit a personal, committed, and critical attitude. Finally, the artistic trajectory supports the flourishing of community or wider ecology as the action research must have meaning and relevance beyond the immediate context the research takes place in (Bradbury Huang, 2010; Moulaert et al., 2016). Figure 6 shows a schematic overview of these four characteristics as applied in the Colour and Shape Heist-Goor trajectory.

Besides grasping social arrangements-like characteristics of artistic collaboration-action research also seeks to bring about desired change as a path to generate knowledge and offer stakeholders the opportunity for actively contributing to their own emancipation. The latter arises from the satisfaction of alienated human needs and through place-related, and thus place-specific, transformative power found in social relationships (Moulaert, 2009; Moulaert \& Mehmood, 2011). Dietvorst (2004) emphasises complementary dimensions of creativity and art within neighbourhood and community development. Here, artistic expressions and communication are inseparable twins. Art can actively be used as a means of communication, as a ground for rediscovering or animating a social identity, as a reconstruction of social relation- ships, a redevelopment of (public) space through social mobilisation in collaboration with neighbourhood communities. This particular action research uses an artistic approach which focuses on assets inherent to collectivelive-presence-art production. Physically attending and doing together are essential elements in our study. The body is seen as the socio-spatial site par excellence through which we all intimately connect with our world.

To further explore place attachment as an embodied socio-spatial process, our study also includes a phenomenological investigation of the first person, wherein the first author uses her (emotional) experiences in making art as a basis or starting point for investigating specific assets of co-creative art. This method aims to involve the worlds of other people (Seamon, 2000, pp. 163-164) and create meaning in their concrete lives and experiences. Understanding phenomena-those things or experiences as human beings experience them-as well as using the phenomenological method, requires both an emotional effort and rational thinking (Bradley, 2007; Hogarth, 2010). This position is supported by findings in neuroscientific research that emotions and cognitions cannot be isolated from each other (Damasio, 2005; Phelps \& LeDoux, 2005). One highlighted asset of making art is the necessity of making many critical decisions, one after the other. Making choices always eliminates possibilities, which can create some inner tension. The asset reveals itself when one is able to release choice-related tension and trust that all options of a process are valuable options. Linked to the previous asset, in making art, it is impossible to say from the start what exactly the result will look like. This asset manifests when one can let go of goal-oriented creating and is able to appreciate the beauty of and in the alternative or unexpected result.

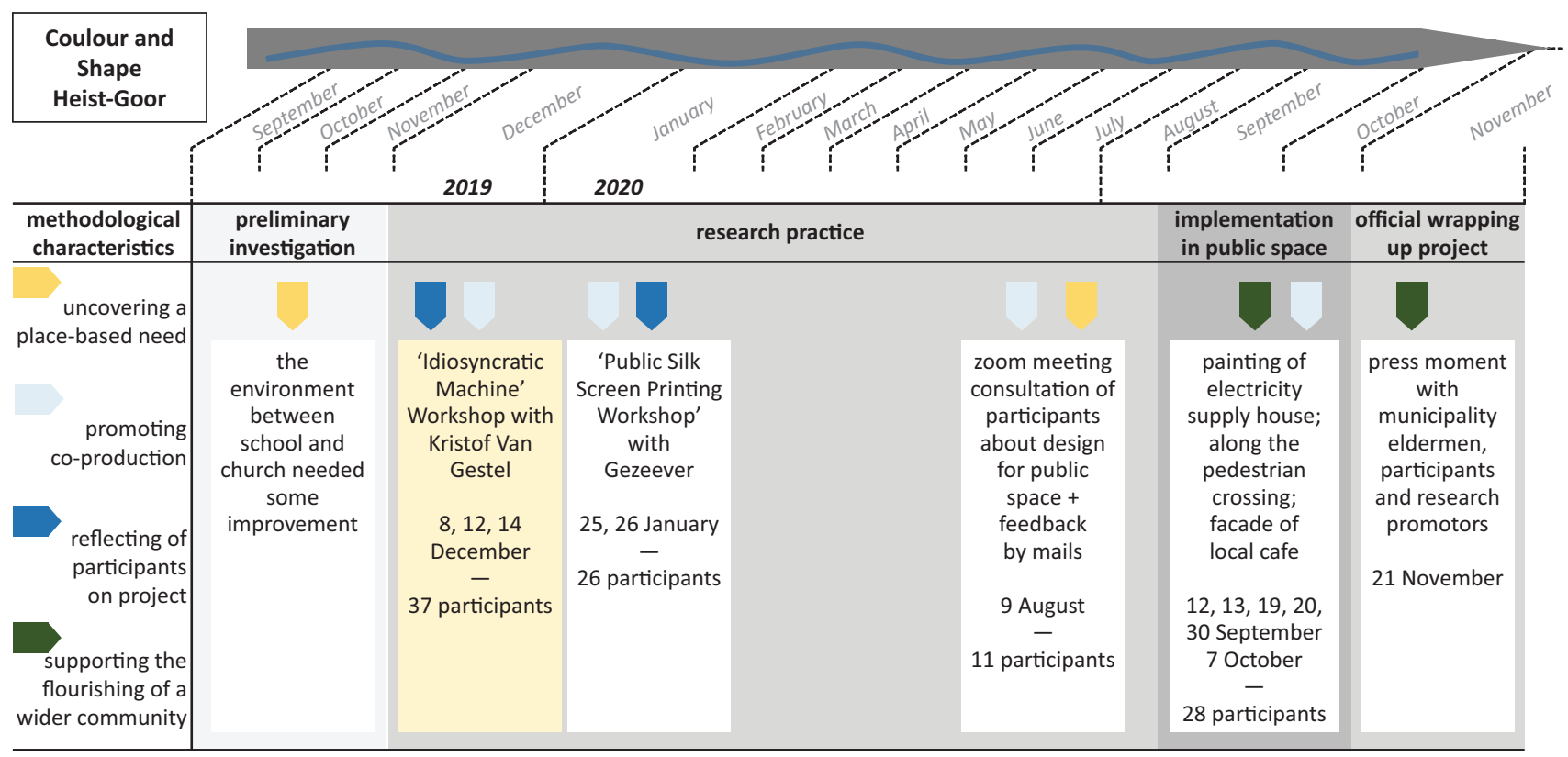

Figure 6. Artistic action research scheme for Colour and Shape Heist-Goor. Source: Ruth Segers. 


\section{Mount Murals' Embodied Artistic Experiences}

Central in our study is not the art product, but the creative process of doing together as a form of conversation and experiencing for oneself. Mount Murals thus affords embodied artistic experiences or everyday actions and experiences that people usually do not consciously recognise when they collaborate but are essential to feelings of commitment and ease. An example are the fine social mechanisms that work between members of a music group or orchestra when they make music together. Musicians automatically tune in to each other's actions, respond to them, and gain new sensory experiences. This section further evaluates the (inter)actions in the IM workshops of the Colour and Shape Heist-Goor art trajectory, which open up such "playing together" to participants. First, the three relational resonating principles are evaluated, followed by a discussion of the two highlighted assets of creating art.

\subsection{Relational Resonating and the Idiosyncratic Machine Workshop}

Participants in the IM workshop started the Colour and Shape Heist-Goor trajectory with outlining the object that triggered an emotional attachment to local place. In this process, the objects' actual shape disappears and is reworked into many random shapes. During this reworking process some-especially young-people developed clear attachment to particular shapes of their own making. During the official opening of the work in public space, nine to eleven months after the workshops, some silk screen prints were on display. Out of the blue a young girl asked for "her" shape. She leafed through the pile of silk screen prints searching for her "yellow kitten." She found the shape and showed people around. She had developed an attachment to a particular yellow shape and recognised it as her "yellow kitten." Three other girls were happy to see that "their shapes" were featured in public space. A participating family of seven was particularly happy to be able to paint "their" outlined objects on the pedestrian crossing. Although the adults too remembered "their" shapes, some of them clearly showed more attachment to the initial, recognisable object shapes, by putting more importance on having those displayed in public space.

Some workshop participants offer insight into how they experienced co-creating in the IM workshop. In general participants have positive sentiments regarding working (very) closely together with people they have never met or know in or from totally different environments:

I thought it was a fun workshop. The object that each brought along was very different and for each of a special value. The togetherness that arose and the spontaneous collaboration made it a nice whole. You notice that one is working with the right colours and the other spontaneously does something. One is very artistic and everyone sees something different. It all turned out to be one whole. In any case, it was very nice to do. (Email, adult woman 1, participant in IM workshop 2)

The people work together very quietly, it was not disturbing that someone came close to me to outline, it was easy to bear, yet I don't know any of the other people. (Recorded interview, mother with young daughter, participant in IM workshop 1)

Feeling together was nice. In laying the shapes I got the feeling [of] "ah I just fit in here, in the whole. I am part of the puzzle." (Recorded interview, adult woman 2, participants of IM workshop 1)

The following two fragments show how the relation with oneself, if juxtaposed to others, can also create tension and depends to a certain extent on the ability to selfregulate and self-soothe. During the IM process, Kristof stresses that participants are free to follow their own rhythm, also, nowhere in the workshop is mentioned what would be criteria of "nice work":

I felt peaceful in the head when you had to draw the figures, especially the outlining of the shapes, both on paper and chalk paper. (Recorded interview, grandmother with granddaughter, Participants of IM workshop 1)

I felt under pressure, as if I could not fetch up with the speed (of cutting) of others. I want to deliver nice work. (Email, adult woman 4, participant of IM workshop 3)

During the IM process, new embodied interactions in participants and between participants and their living environment are simultaneously stimulated:

In a time span of an hour and a half my mindset evolved considerably, from "what am I cutting here while my desk is bulging with work" to "now I'm colouring with dots, damned, what did I do to myself?" to "maybe I can do something with this?" The further the evening progressed, the more I saw the point and meaning of what initially seemed useless to me. The head of an accountant will never be artistic, but I really liked the entertaining aspect of the workshop. I compare it a bit with football, you combine and you play together, and sooner or later you can cheer when that goal is scored. (Email, café owner and accountant, adult man, participant in IM workshop 2)

Thank you for the great experiences last night. I thought it was a fun and educational evening. You can hardly believe that you can achieve this result 

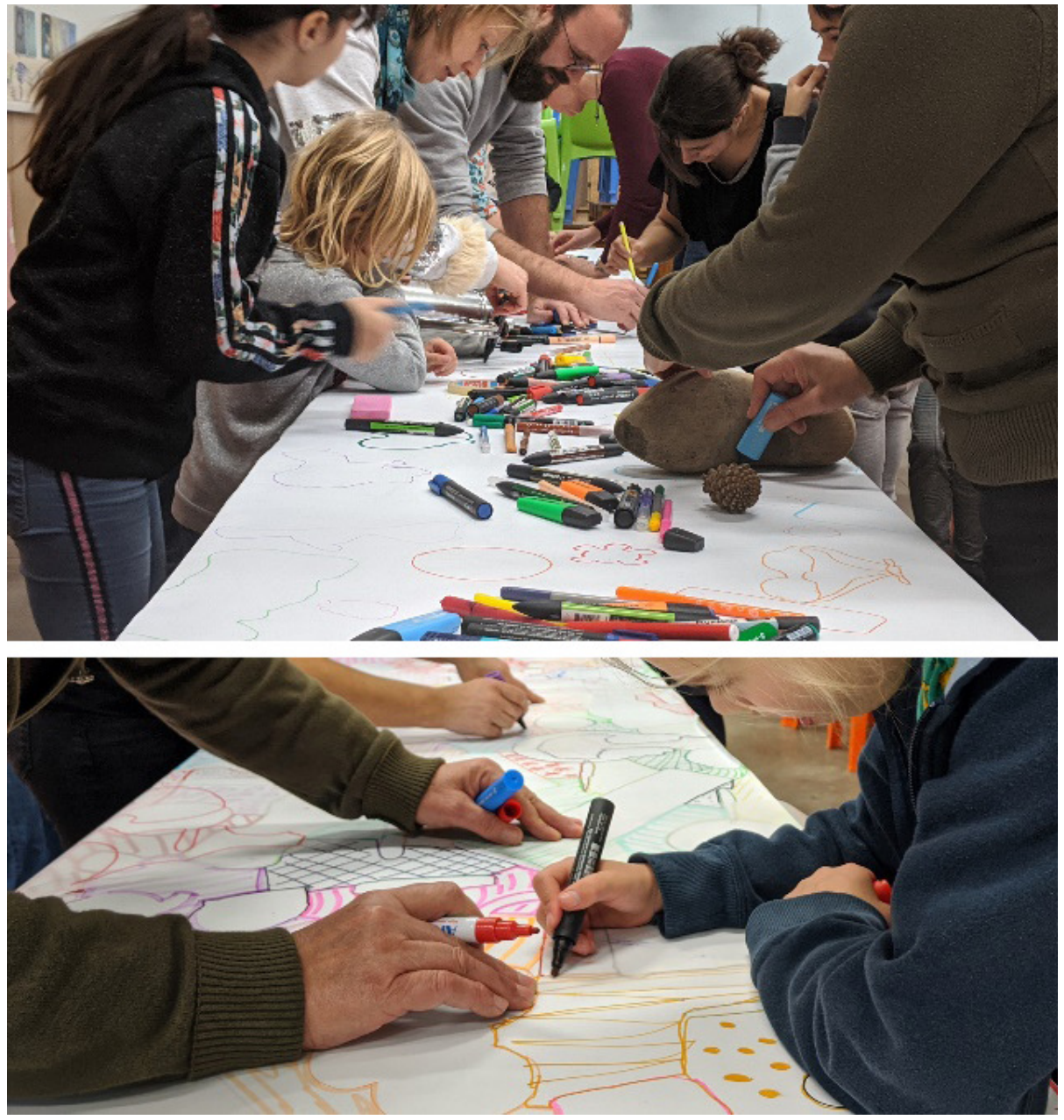

Figure 7. Peaceful alignment through co-creation (picture above) and co-regulation (picture below). Picture below shows a girl being supported by her grandmother in outlining a shape on chalk paper, from IM workshop 1. Both offer opportunities to experience and develop emotional attachment. Source: Ruth Segers.

in such a short period of time. In this way you also learn that people, who you do not expect here, enjoy the evening (it was also a nice and pleasant group). I went home with a satisfied feeling and I thought back a few times today about what we all did and in what order we arrived at the end result. Even now I still have a good feeling when I think of it, I'm glad I came. The interaction with those present made me feel good. So I look forward to a follow-up and I would like to be invited. (Email, adult woman 3, participant in IM workshop 2)

\subsection{Assets of Art Creation}

The IM offers a very accessible way of being creative while connecting with people of various generations and backgrounds. It does so by focusing on actions, situations and experiences that are inherent to making art (because it actually is making art), but without the need for artistic (or any other) education. These situations incorporate beneficial assets of creating art that are valued as essential life skills.
As mentioned in Section 3, in the IM, participants are confronted with (the art of?) decision making in simple, yet obvious ways. Working fast or slowly? How big may these shapes be? Moreover, because it is a collective work, every participant is at the same time involved with creating (what shape, colour, shading do I prefer?) and relating (what colour, shape, shading is the other choosing and how do I react?). Every participant has to find a personal, often intuitive, answer to those questions. When one chooses a particular felt pen, with a particular colour and thickness, for example, this colour and thickness carries an implicitly felt personal and emotional value. However, this choice is co-influenced by the context of the art work in progress. One chooses not only a colour of preference, but simultaneously a colour that matches (or not) the colours chosen by other participants.

Linked to the previous asset, in making art, it is impossible to say from the start what exactly the result will look like. During the IM workshops, Kristof reveals the creative instructions bit by bit, so it is impossible to think or act by predisposition. In the Colour and Shape 
Heist-Goor trajectory the IM process was repeated three times. In a way the final product of each workshop undeniably bears the signature of its designer, Kristof. However, a closer look reveals that each result does have its own identity: from chaotic to structured, from spontaneous to highly contrived, from unambiguous to complex. Also, while cutting shapes, Kristof points out that there is always the "other side," the negative of the shape. In some cases, this alternative looks more appealing than the expected outcome. As a result, there is always self-reflection involved, consideration of what already exists and there is never one way to go.

The "landscapes of shapes" resulting from the IM workshops display alternative outcomes of co-creation and co-regulating. Because each landscape results from unspoken agreement, or a group negotiation, we also see that co-regulating and co-creating is a unique given with unique effects. Figure 8 presents the outcomes of workshop 1, a cooperation of 19 persons with a majority of children, and that of workshop 2, a cooperation of eight adults, including one artist. Moreover, negotiation between participants includes choice making and brings in different preferences (like assorted colours or not) and capacities (like fine motor skills) of participants. Finally, the fact that participants recognise their particular contributions, which have changed from placerelated object to shape, makes space for refocused or evolved place attachment. Especially since the shapes have been painted in a characteristic local public space.

\section{Conclusions}

This article analysed to what extent, how and under which conditions Mount Murals' collective art trajectory Colour and Shape Heist-Goor supports an evolving place attachment among its participants. This artistic action research has been co-inspired by the challenges local Flemish authorities face in sustainably addressing the changes of everyday life in villages and towns. How to address wavering feelings of sense of belonging among inhabitants of Heist-op-den-Berg?

This article combined socio-spatial theory based on, among others, experiences of participation in community building in spatial planning, recent insights from relational neuroscience as applied in artistic therapy and knowledge about assets of art creation. From sociospatial theory it deployed the concept of sense of belonging and more in particular place attachment, which refers to feelings of comfort, security, and inclusion or being part of this environment. It argued that place attachment should be regarded as an infinite ongoing process of re-connecting with place or the effective outside world we live in. It is exactly this outside world, like geography, nature, material objects, which provides a perfect medium for renegotiating and rejuvenating social relations.

Because place attachment is a dynamic process it can be invigorated and given direction. Our study linked place attachment with relational resonating, an overarching notion that refers to the smooth and stable relationship we enter whenever we feel attuned in interaction with another being. The benefit of experiencing this particular relationship and the inherent ability to be able to fine-tune our emotions is that it updates our autobiographical memory and contributes to acquiring attachment. The attunement can be animated through, e.g., co-creation, co-regulation, which are co-resonating principles. These principles naturally occur during the process of physically creating in a collective way.

In the Colour and Shape Heist-Goor art trajectory, the first author enriched the principles of relational resonating by uploading them with place-related sentiments and studied them at work in actions or embodied experiences during three IM workshops. To mobilise insights, the co-creative art trajectory was developed as an action research in which the result and the process of making can be seen as art. During these workshops, we assessed two assets of art creation at work: the need to
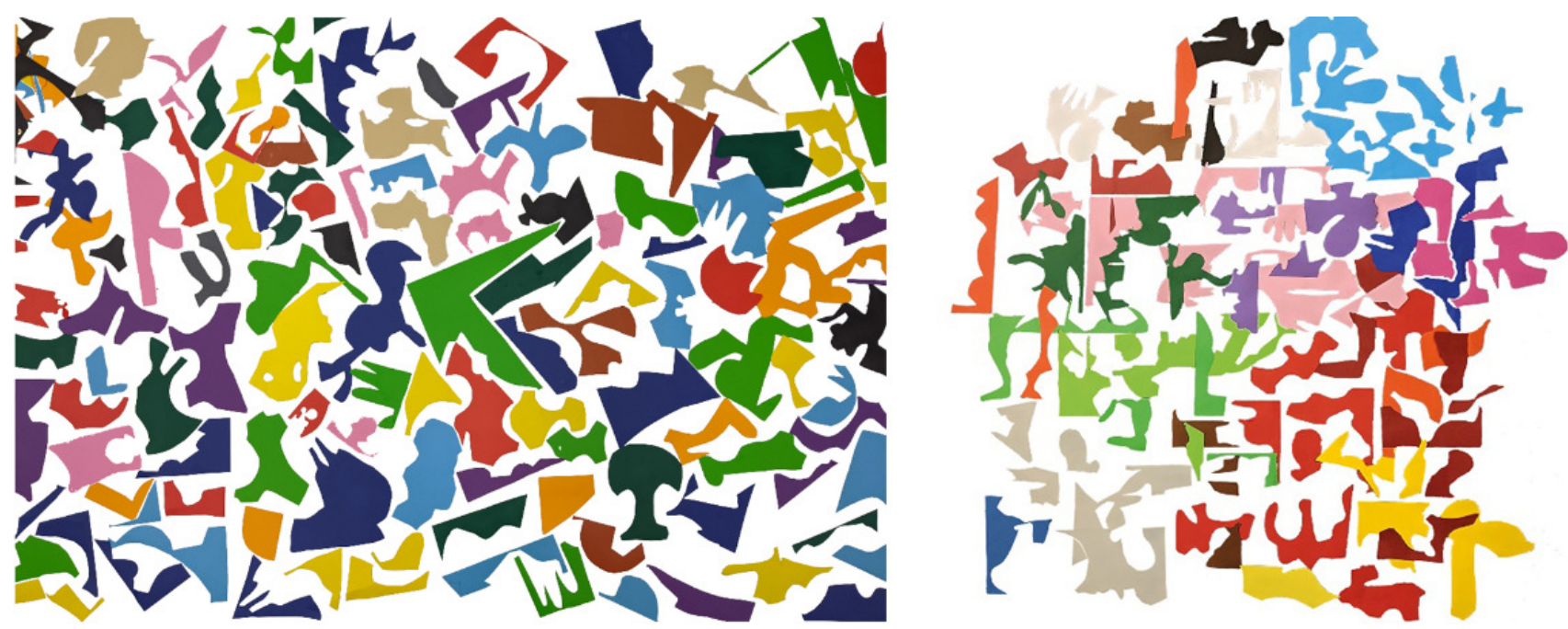

Figure 8. Two IM landscapes: The Colour and Shape Heist-Goor workshops 1 and 2, series 1 outcomes. Source: Ruth Segers. 
continuously take critical decisions and the impossibility to know the final result of a creative process in advance. The assets basically reflect essential life skills.

Mount Murals' co-creative art trajectory Colour and Shape Heist-Goor started in August 2019 and finished in November 2020. Investigating the participants' evolving place attachment over the time showed that they are willingly showing their emotions of attachment to persons and places when symbolised by objects. The art trajectory further revealed that the connection to place is deepened by interpersonal interaction through artistic co-creation, via an attachment process of making co-created shapes. This happens both in children and adults but was more pronounced in children. Participating in the art trajectory simultaneously opened up possibilities for creating or deepening interpersonal, and especially intergenerational, connection.

The municipality of Heist-op-den-Berg put forward its church village Heist-Goor because its inhabitants in particular display an outspoken disinterest in commitment to organising or reviving local community life. The Colour and Shape Heist-Goor trajectory did succeed in reviving or awakening feelings of attachment to place and stimulate the inclusion of parts of the population. In this small community, having 70 participants in a new artistic venture is an accomplishment. In this case, an important part of the impetus of taking part was the prospect of (grand)parents to share in a creative way their sense of belonging with their offspring, and in doing so improve a characteristic place in the village which simultaneously signifies their shared belonging.

In a way sense of belonging is a unique and vital mental health concept that relates to social inclusion, for it refers to our deepest need of security through attachment, to a place that entails the relationship we call "home." Attachment demands involvement. Concurrently, our study has its limits regarding inclusivity. Maybe most of all because it attracts people who have a soft spot for the particular creativity this project afforded.

Our study discussed place-related relationships. It looked at actions and experiences that enhance social connection through place, without relapsing in the rhetoric of identity. Connecting with place not only demands time; place also and inevitably evolves over time: If only because the earth not only rotates around its axis, but also moves through the universe. This reassuring insight supports and offers an opening and a need to stimulate evolving place attachment, for "without exception home is considered to be the place of greatest personal significance in one's life," in fact it is "the central reference point of human existence" (Relph, 1976, p. 20).

\section{Acknowledgments}

This research was financially supported by the Flemish Agency for Innovation and Entrepreneurship (VLAIO). Thank you to Tessy Gorris of the Heist-op-den-Berg
Planning Office who was a supporting guide through the full process of the Colour and Shape Heist-Goor art trajectory. Thank you to artists Kristof van Gestel and Hilde Overbergh for their invaluable creative contributions to the pilot trajectory.

\section{Conflict of Interests}

The authors declare no conflict of interests.

\section{References}

Badenoch, B. (2008). Being a brain-wise therapist: A practical guide to interpersonal neurobiology. Norton.

Baumeister, R. F., \& Leary, M. R. (1995). The need to belong: Desire for interpersonal attachments as a fundamental human motivation. Psychological Bulletin, 117, 497-529.

Bossuyt, T. (2019). Collective exercises in free thought and action. In K. Van Gestel (Ed.), Idiosyncratic machine (pp. 198-215). APE.

Bradbury Huang, H. (2010). What is good action research? Why the resurgent interest? Action Research, 8, 93-109.

Bradley, T. B. (2007). The psychophysiology of intuition: A quantum-holographic theory of nonlocal communication. World Futures, 63, 61-97.

Damasio, A. (2005). Descartes' error: Emotion, reason, and the human brain. Penguin.

Dietvorst, E. (2004). The return of the swallows. From urban hardship to identity retrieval-The making of a movie as a social integration project in Brussels South. City, Analysis of Urban Trends, Culture, Theory, Policy, Action, 8(2), 279-288.

Fitzgerald, J. (2018). Close to home, local ties and voting radical right in Europe. Cambridge University Press.

Gregory, D., \& Urry, J. (1985). Social relations and spatial structures. Palgrave Macmillan.

Hagerty, B. M., Lynch-Sauer, J., Patusky, K., Bouwsema, M., \& Collier, P. (1992). Sense of belonging: A vital mental health concept. Archives of Psychiatric Nursing, 6(3), 172-177.

Harrison, S., \& Dourish, P. (1996). Re-place-ing space: The roles of place and space in collaborative systems. In Proceedings of the 1996 ACM conference on computer supported work (pp. 67-76). https://doi.org/ 10.1145/240080.240193

Hass-Cohen, N., \& Findlay, J. C. (2015). Art therapy and the neuroscience of relationships, creativity, and resiliency. Skills and practices. W.W. Norton \& Company.

Hay, R. (1998). Sense of place in developmental context. Journal of Environmental Psychology, 18, 5-29.

Hayden, D. (1995). The power of place: Urban landscapes as public history. MIT Press.

Heist-op-den-Berg vroeger en nu. (2020, September 23). 21 kinderen en 41 gewone mensen van het Goor werkten mee aan dit artistieke traject van Mount 
Murals [21 children and 41 ordinary people of Goor participated in this artistic trajectory of Mount Murals; Facebook status update]. https:// www.facebook.com/HeistOpDenBergVroegerEnNu/ photos/a.582787325078631/3645824675441532

Hidalgo, M. C., \& Hernandez, B. (2002). Attachment to the physical dimension of places. Psychological Reports, 91, 1177-1182.

Hogarth, R. M. (2010). Intuition: A challenge for psychological research on decision making. Psychological Inquiry, 21(4), 338-353.

Hughes, A. E., Crowell, S. E., Uyeji, L., \& Coan, J. A. (2012). An emotion dysregulation and social baseline theory. Journal of Abnormal Child Psychology, 40(1), 21-33.

Hunter, C. D., Case, A. D., Joseph, N., Mekawi, Y., \& Bokhari, E. (2017). The roles of shared racial fate and a sense of belonging with African Americans in Black immigrants' race-related stress and depression. Journal of Black Psychology, 43(2), 135-158.

Marsh, K. L., Johnston, L., Richardson, M. J., \& Schmidt, R. C. (2009). Toward a radically embodied, embedded social psychology. European Journal of Social Psychology, 39, 1217-1225.

McLaren, S., \& Challis, C. (2009). Resilience among men farmers: The protective roles of social support and sense of belonging in the depression-suicidal ideation relation. Death Studies, 33(3), 262-276.

Moser, M.-B., Rowland, D. C., \& Moser, E. I. (2015). Place cells, grid cells, and memory. Cold Spring Harbor Perspectives in Biology, 7. https://cshperspectives.cshlp. org/content/7/2/a021808

Moulaert, F. (2009). Social innovation: Institutionally embedded, territorially (re)produced. In D. MacCallum, F. Moulaert, J. Hillier, \& S. Vicari Haddock (Eds.), Social innovation and territorial development (pp. 11-24). Ashgate.

Moulaert, F., \& Mehmood, A. (2011). Spaces of social innovation. In A. Pike, A. Rodriguez-Pose, \& J. Tomaney (Eds.), Handbook of local and regional development (pp. 212-225). Routledge.

Moulaert, F., Segers, R., Van den Broeck, P., Van Dyck, B., Miciukiewicz, K., Schreurs, J. \& Servillo, L. (2016). SPINDUS methodological synthesis. A metaframework for not getting lost in space. In R. Segers, P. Van den Broeck, A. Z. Khan, F. Moulaert, J. Schreurs, B. De Meulder, K. Miciukiewicz, G. Vigar, \& A. Madanipour (Eds.), The SPINDUS handbook for spatial quality. A relational approach (pp. 266-302). ASP.

Pérez Liebergesell, N., Vermeersch, P.-W., \& Heylighen, A. (2021). The hidden unwelcome: How buildings speak and act. Journal of Interior Design. Advance online publication. https://doi.org/10.1111/joid.12203

Phelps, E. A., \& LeDoux, J. E. (2005). Contributions of the amygdala to emotion processing: From animal models to human behavior. Neoron, 48, 175-187.

Proshansky, H., Fabian, A., \& Kaminoff, R. (1983). Placeidentity: Physical world socialisation of the self. Journal of Environmental Psychology, 3, 57-83.

Relph, E. T. (1976). Place and placelessness. Pion.

Relph, E. T. (2015, October 20). Place cells and sense of place in neuroscience. Placeness. http://www. placeness.com/place-cells-and-sense-of-place-inneuroscience

Richardson, M. J., Marsh, K. L., Isenhower, R. W., Goodman, J. R. L., \& Schmidt, R. C. (2007). Rocking together: Dynamics of intentional and unintentional interpersonal coordination. Human Movement Science, 26, 867-891.

Seamon, D. (2000). A way of seeing people and place: Phenomenology in environment-behaviour research. In S. Wapner, J. Demick, T. Yamamoto, \& H. Minami (Eds.), Theoretical perspectives in environment-behaviour research. Underlying assumptions, research problems and methodologies (pp. 157-178). Kluwer Academic Publishers.

Segers, R. (2018). First-generation Turkish women in the 2060 neighbourhood of Antwerp. Tijdschrift voor Genderstudies, 21(4), 325-340.

Segers, R. (2020, September 20). Lieve dame dankuwel voor het mooi maken van ons dorp [Dear lady thank you for beautifying our village; Facebook status update] https://www.facebook.com/ruth.august. 5851

Sennet, R. (2012). Together: The rituals, pleasures and politics of cooperation. Penguin Group.

Siegel, D. J. (2012). The developing mind: How relationships and the brain interact to shape who we are (2nd ed.). Guilford.

Stedman, R. C. (2002). Towards a social psychology of place: Predicting behavior from place-based cognitions, attitudes, and identity. Environment and Behavior, 34(5), 561-581.

Tronick, E., \& Beeghly, M. (2011). Infants' meaning making and the development of mental health problems. American Psychologists, 66(2), 107-119.

Tuan, Y.-F. (1975). Place: An experiential perspective. Geographical Review, 65(2), 151-165.

Twigger-Ross, C., \& Uzzel, D. L. (1996). Place and identity processes. Journal of Environmental Psychology, 16, 205-220.

Van Cauteren, P. (2019). Letter to Kristof Van Gestel. In K. Van Gestel (Ed.), Idiosyncratic machine (pp. 34-39). APE.

Zeisel, J. (2006). A sense of place. New Scientist, 189(2541), 50-55. 


\section{About the Authors}

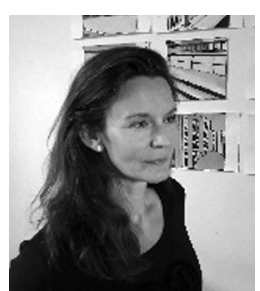

Ruth Segers is a political scientist with a creative mind, an eye for detail, and a broad field of interest. She has been a research member of the Planning \& Development Research Unit of the Department of Architecture (KU Leuven) since 2007, the place where she developed a soft spot for topics that involve the relationship between (public) space and interpersonal interaction. Hence her PhD on this subject (2018). In 2019 she obtained a VLAIO Innovation Mandate for her Mount Murals project.

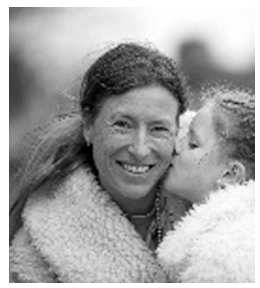

Karin Hannes is associate professor at the Faculty of Social Sciences, KU Leuven, and coordinates the research group SoMeTHin'K (Social, Methodological and Theoretical Innovation/Kreative). Her main research interest is in developing, applying, and refining approaches to qualitative research. She is most known for her academic contributions in the area of qualitative evidence synthesis. On a primary research level, she has been focusing on the use and further development of arts-based, multisensory, and place-based research methods in the context of public health, social welfare practices, urban development, and the arts and design sector.

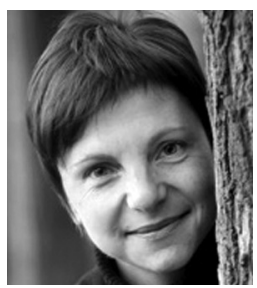

Ann Heylighen is a design researcher with a background in architectural engineering. As a professor of design studies at KU Leuven, she co-chairs the Research[x]Design group at the interface of design research and social sciences/humanities. Her work explores how human diversity may expand prevailing ways of understanding and designing space. Ann studied at KU Leuven and ETH Zürich and conducted research at Harvard and UC Berkeley. She is a fellow of the Design Research Society and associate editor of Design Studies.

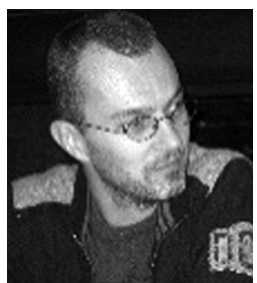

Pieter Van den Broeck is professor of spatial planning and sustainable development in the Department of Architecture at KU Leuven, where he leads the research unit Planning \& Development (P\&D). Pieter has over 20 years of experience in the field of spatial development analysis and planning, in both research and practice. From a critical institutionalist perspective and a methodological interest in transdisciplinary action research, he engages in research on planning instruments, social innovation, and territorial development, governance of socio-ecological systems, and land policies and commons. 